\title{
THE INFLUENCE OF DIETARY INTERVENTIONS ON PARACLINICAL PARAMETERS IN PATIENTS WITH METABOLIC SYNDROME
}

\author{
Timea C. GHITEA ${ }^{1}$, Raluca A. CORB ARON ${ }^{1}$, Liviu LAZAR $^{1}$, Simona BUNGAU ${ }^{1 *} \bowtie$ \\ ${ }^{1}$ Faculty of Medicine and Pharmacy, University of Oradea, Oradea, Romania
}

Received 20 Sept 2020, Accepted 30 Oct 2020

https://doi.org/10.31688/ABMU.2020.55.4.05

\section{Abstract}

Introduction. Patients with metabolic syndrome (MS) frequently present alterations of paraclinical tests. The effectiveness of dietary intervention has been intensively studied in the last decade.

The objective of the study. This research studied the correlation of uric acid with the evolution of paraclinical parameters (HOMA index, cholesterol, triglycerides and C-reactive protein) in patients with MS, following the evolution of specific imbalances in MS, after an anti-inflammatory diet, associated or not with sport.

Materials and methods. The monitoring of the parameters was performed over a period of 12 months, on a number of 110 patients, aged $>18$ years, with HOMA index> 2, divided into three groups: control group, diet therapy group, and diet therapy and sports group, respectively.

Results. Following the statistical processing, the correlation of the paraclinical parameters indicates the following: uric acid and cholesterol - Pearson coefficient $\mathrm{r}=0.192, \mathrm{p}<0.05$; uric acid and triglycerides $-\mathrm{r}=0.544$, $\mathrm{p}<0.001$; uric acid and C-reactive protein $-\mathrm{r}=0.443$,

\section{Résumé}

L'influence des changements diététiques sur les paramètres paracliniques chez les patients avec du syndrome métabolique

Introduction. Les patients atteints du syndrome métabolique (SM) présentent fréquemment des altérations des tests paracliniques. L'efficacité de l'intervention diététique a été étudiée de manière intensive au cours de la dernière décennie.

L'objectif de l'étude. Cette recherche a suivi la corrélation de l'acide urique avec l'évolution des paramètres paracliniques (indice HOMA, cholestérol, triglycérides et protéine C-réactive) chez des patients atteints de SM, suivant l'évolution de déséquilibres spécifiques de la $\mathrm{SM}$, après un régime anti-inflammatoire, associé ou non avec le sport.

Matériaux et méthodes. Le suivi des paramètres a été réalisé sur une période de 12 mois, sur un nombre de 110 patients, âgés de> 18 ans, d'indice HOMA>2, répartis en trois groupes : groupe témoin, groupe diététique, groupe diététique et sportif, respectivement.

Résultats. Suite au traitement statistique, la corrélation des paramètres paracliniques indique les éléments 
$\mathrm{p}<0.001$; HOMA index and uric acid $-\mathrm{r}=0.223$, $\mathrm{p}$ $<0.05$.

Conclusions. The results of this study indicate that after dietary interventions combined with physical activity, the metabolic imbalances were reduced in patients with MS. At the same time, the evolution of paraclinical parameters, in the control group, indicates an evolution of the disease in the absence of nutritional intervention. The correlation of paraclinical parameters indicated a strongly positive and directly proportional link.

Keywords: HOMA index, cholesterol, triglycerides, uric acid, C-reactive protein, metabolic syndrome.

\section{Abbreviations list}

BIA - bioelectrical impedance analysis BMI - body mass index

$\mathrm{CG}$ - control group

CRP -C-reactive protein

DTG - diet therapy group

DTSG - diet therapy and sports group

HDL-C - high-density lipoprotein cholesterol

HOMA - homeostasis model assessment

IgG - immunoglobulin $G$

Mc - mean control group

$\mathrm{Md}$ - mean diet therapy group

Mds - mean diet therapy and sports group

MS - metabolic syndrome

NF-אB - nuclear factor kappa-light

WPHNA - World Public Health Nutrition Association

\section{INTRODUCTION}

Metabolic syndrome (MS), known as a group of cardiovascular risk factors associated with insulin resistance, high blood pressure, glucose intolerance, hypertriglyceridemia and low levels of high-density lipoprotein cholesterol (HDL-C), is a major public health issue worldwide ${ }^{1}$. Insulin resistance has a complex and heterogeneous genetic background. Considering the essential roles of the pathways involved in the pathogenesis of insulin resistance in liver and muscles, understanding the molecular mechanism of insulin resistance is vital for the development of new and effective therapies for metabolic disorders. The homeostasis model assessment index (HOMA) for insulin resistance was calculated as the product of fasting insulinemia (in microunits per milliliter) and fasting glycaemia (in millimoles per liter), divided by $22.5^{2}$. Higher HOMA values indicate greater insulin resistance. Genetic and epidemiological studies suggest that insulin resistance is, at least in part, genetically determined. Numerous genes have been suggested as suivants : acide urique et cholestérol - coefficient de Pearson $\mathrm{r}=0,192, \mathrm{p}<0,05$; acide urique et triglycérides $-\mathrm{r}=0,544, \mathrm{p}<0,001$; acide urique et protéine C-réactive - $\mathrm{r}=0,443, \mathrm{p}<0,001$; Indice HOMA et acide urique $-r=0,223, p<0,05$.

Conclusions. Les résultats de cette étude indiquent qu'à la suite des interventions diététiques associées à une activité physique, les déséquilibres métaboliques ont été réduits chez les patients atteints de SM. Dans le même temps, l'évolution des paramètres paracliniques, dans le groupe témoin, indique une évolution de la maladie en l'absence d'intervention nutritionnelle. La corrélation des paramètres paracliniques indiquait un lien fortement positif et directement proportionnel.

Mots-clés: indice HOMA, cholestérol, triglycérides, acide urique, protéine C-réactive, syndrome métabolique.

potential candidates for insulin resistance, but the results of these studies have been controversial.

Food intolerances are common in MS, paraclinically manifested by increased $\operatorname{IgG}$ values. This type of antibody is found in all body fluids and protects against bacterial and viral infections. The reaction may be due to an alteration in intestinal permeability, which occurs in permeable bowel syndrome. The intestine becomes irritated either due to stress or due to the consumption of antibiotics or diet rich in sugar or saturated fats that lead to damage of the intestinal flora. Long-term inflammation, caused by continued use of foods that cause this IgG reaction, can lead to autoimmune disease ${ }^{3}$. In this type of food allergy (which is a delayed allergic reaction), the immune system produces specific IgG III antibodies (class G immunoglobulins). These antibodies determine inflammatory processes. Symptoms may occur up to three days after eating the inflammatory food ${ }^{4}$.

The link between visceral fat and associated MS pathology was observed in a study published in $2013^{5}$, noting dysfunctional subcutaneous adipose tissue 
expansion and ectopic triglyceride storage, indicating extended cardiovascular risk. Uncontrolled intake of saturated fatty acids in the control group led to increased values of triglycerides, which was observed in a study published in 2014, that also assessed visceral fat ${ }^{6}$.

\section{THE OBJECTIVE OF THE STUDY}

The present study aimed to follow the evolution of paraclinical parameters correlated with MS (HOMA index, cholesterol, triglycerides, uric acid and C-reactive protein (CRP)), under diet therapy or diet therapy combined with sports, in patients with MS. A personalized anti-inflammatory diet therapy, adapted to existing pathologies, was combined with identifying the foods that give allergic reactions of IgG type, managed according to the specialized provisions, in order to find the most suitable formula that improves the verified parameters.

\section{Materials AND Methods}

The study was performed on 110 subjects diagnosed with MS, who presented to a private nutrition and diet therapy office in Oradea, Romania, to verify the nutritional status during 2018-2020. Patients $>18$ years of age with HOMA index $>2$ were included in the study. The presence of medical complications and insulin-dependent diabetes were exclusion criteria. The evolution of visceral fat, BMI and paraclinical parameters was compared in patients who underwent diet therapy or diet therapy associated with sports vs. those who maintained the same lifestyle. Patients were divided into 3 groups using a selection method based on their preference to follow or not diet therapy and a sports program, but also on the medical history and assessment of the risks / benefits of therapeutic interventions for each patient: diet therapy group (DTG, $n=58$ ), diet therapy and sports group (DTSG, $n=32$ ) and control group (CG, $n=20)$. In the 3 groups, the paraclinical parameters body mass index (BMI) and fat mass were monitored. Diet therapy was individualized for each subject, being the most specific in the DTSG group (for increasing muscle mass, with increasing protein intake from 20-25\% to $30-35 \%$, without concomitant increase in lipid intake). Carbohydrates were the staple food, accounting for $50-55 \%$ of the total daily intake. The recommended proteins were $85 \%$ of plant origin and $15 \%$ of animal origin. The physical activity program consisted of aerobic exercises practiced 5 times / week (minimum 20 minutes) for cardiovascular stimulation.

After inclusion in the study, the protocol consisted in following the adherence to diet therapy and sports and the evolution of the assessed parameters, presenting the results obtained at 12 months, compared to the initial ones, for all three groups.

The study was carried out with the agreement of the Ethics Commission of the Faculty of Medicine and Pharmacy of the University of Oradea, Romania (12/ 01.04.2019). Each patient in this research signed an informed consent form prior to inclusion.

The clinical evaluation was performed with a bio-electric impedance body analyzer (Tanita MC780MA, Germany), agreed by the World Public Health Nutrition Association; ; specialized, medical software that allowed following the clinical parameters evolution. The procedure requires the patient to climb barefoot on the analyzer, holding 2 electrodes in his hand. The BIA evaluates the body composition (conducting a low current through the body) and measures the impedance difference. Fat and lean tissues having different electrical properties, information is obtained on body weight, fat mass, muscle mass, bone mass, visceral fat, sarcopenic index, metabolism, intracellular water, extracellular water, angle phase.

The HOMA index (ratio between insulinemia and blood glucose) reflects the balance between hepatic glucose production and insulin secretion of pancreatic $\beta$ cells. At insulin resistance, the body has a characteristic response, different from the normal level (<2); its high levels, along with dyslipidemia and hypertension are the basis for the diagnosis of MS. Blood tests are done from venous blood, collected in the morning, on an empty stomach. Values are considered normal $(<2)$, possible insulin resistance $(>2)$, increased likelihood of insulin resistance (>2.5), and mean value in diabetics $(>5)$.

Cholesterol, triglycerides, uric acid and CRP from blood were also tested in laboratory; values above normal were rated "1" (cholesterol $>200 \mathrm{mg} / \mathrm{dL}$, triglycerides $>150 \mathrm{mg} / \mathrm{dL}$, uric acid $>7 \mathrm{mg} / \mathrm{dL}$ in men and $>5.7 \mathrm{mg} / \mathrm{dL}$ in women, CRP> $0.5 \mathrm{mg} / \mathrm{dL}$ ), and the values that did not exceed the normal limits were marked with "0".

Statistical analysis was performed using SPSS Statistics 22. All mean parameter values, standard deviations, frequency intervals and tests of statistical significance were calculated using the t-Student test. The distribution of the groups proved to be similar to the normal one, being used by hypotheses involving numerical data. The Bravais-Pearson correlation coefficient was used to calculate an independent indicator of the units of measurement of the two variables. The $p<0.05$ value was attributed to statistical significance. ANOVA with a post-hoc analysis (Bonferroni) was used to analyze the differences between the groups, as a further analysis of the subgroups. 
Table 1. Medium initial paraclinical characteristics.

\begin{tabular}{|c|c|c|c|c|c|c|}
\hline \multirow[b]{2}{*}{ Parameters } & \multicolumn{2}{|c|}{ CG } & \multicolumn{2}{|c|}{ DTG } & \multicolumn{2}{|c|}{ DTSG } \\
\hline & & $\begin{array}{l}\text { Standard } \\
\text { deviation }\end{array}$ & & $\begin{array}{l}\text { Standard } \\
\text { deviation }\end{array}$ & & $\begin{array}{l}\text { Standard } \\
\text { deviation }\end{array}$ \\
\hline HOMA index & 3.15 & 1.2258 & 5.93 & 14.3259 & 3.93 & 2.6000 \\
\hline Cholesterol & 0.65 & 0.4893 & 0.72 & 0.4508 & 0.50 & 0.5080 \\
\hline Triglycerides & 0.35 & 0.4893 & 0.63 & 0.4848 & 0.43 & 0.5040 \\
\hline CRP & 0.45 & 0.5104 & 0.50 & 0.5043 & 0.34 & 0.4825 \\
\hline Uric acid & 0.20 & 0.4103 & 0.50 & 0.5043 & 0.28 & 0.4568 \\
\hline
\end{tabular}

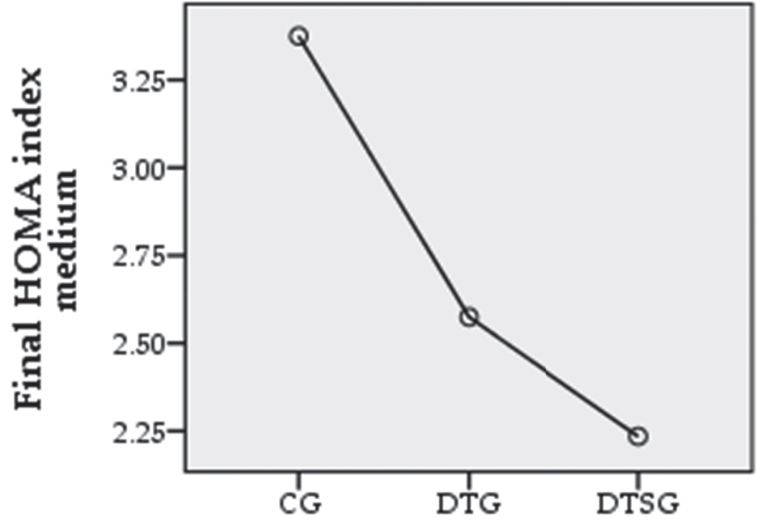

(a)

Group

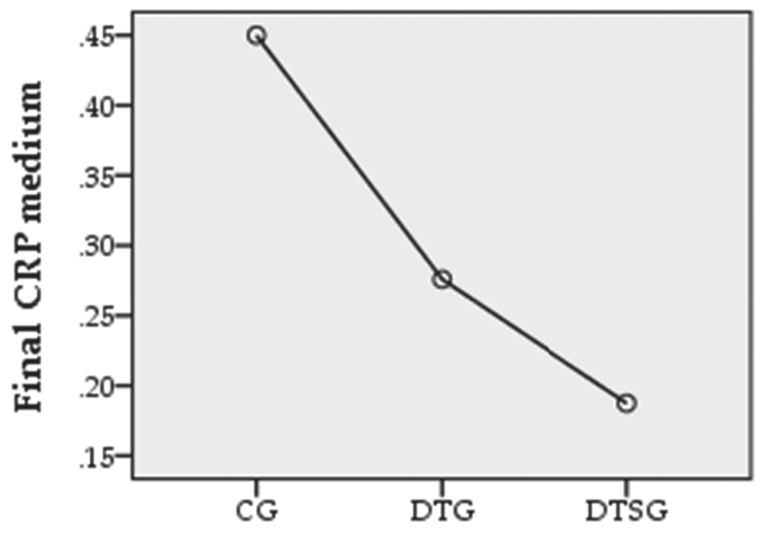

(c)
Group

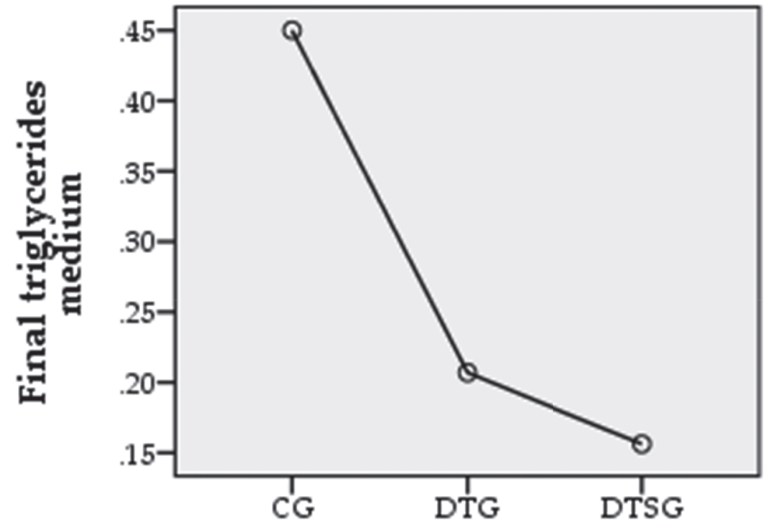

(b)

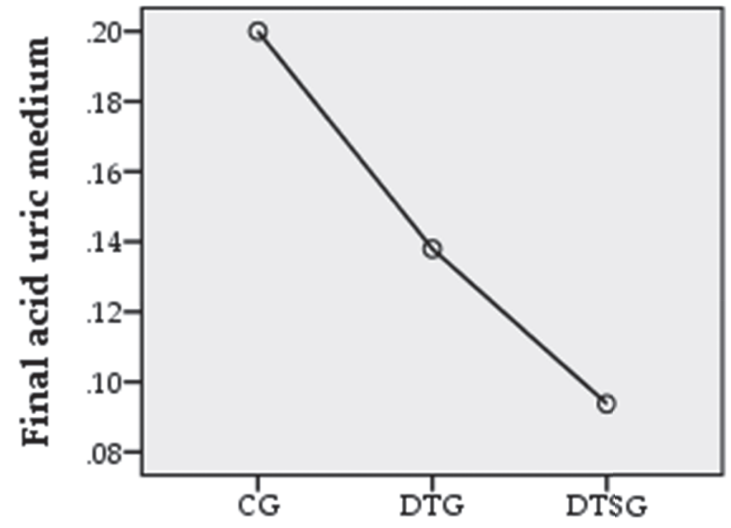

(d)

\section{Group}

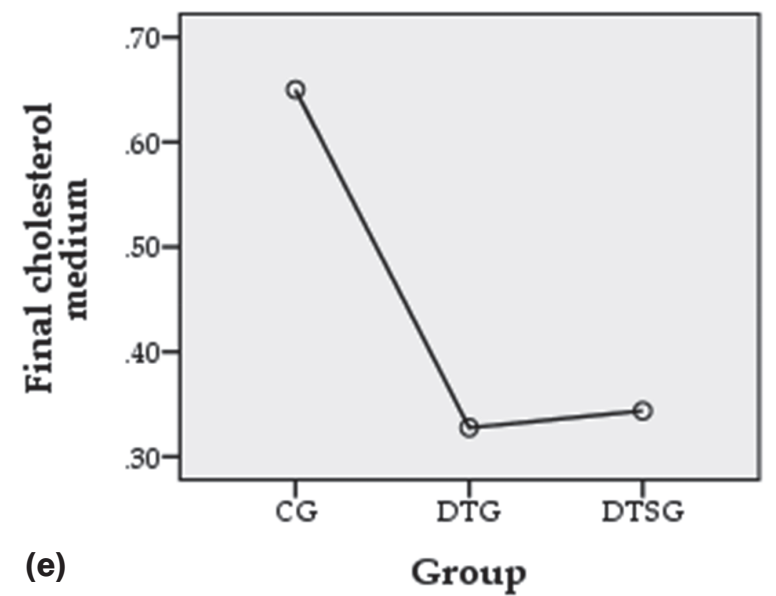

Figure 1. Graphical representation of the average (a) HOMA index, (b) triglycerides, (c) CRP, (d) uric acid and (e) cholesterol at the end of the research period, in all 3 groups. 


\section{ResULTS}

At the initial assessment, the 3 groups were relatively homogeneous in terms of clinical and demographic characteristics, with no statistically significant differences, with a mean age of $37.4909 \pm 14.1212$ years. The initial average values of the monitored parameters are shown in Table 1.

\section{Evolution of paraclinical parameters}

After processing the statistical data with the ANOVA statistical test (for the 3 independent groups) and with the POST HOC BONFERRONI test (for 2 independent groups) it was obtained:

- Concerning the effect of the type of intervention on the HOMA index assessment, $\mathrm{F}=2.517$, $\mathrm{p}=0.085$, at post-testing (after one year), the HOMA index does not differ significantly, as can be seen in Figure 1(a) for the 3 groups. Between CG and DTG $\mathrm{p}>0.05(\mathrm{Mc}=3.37, \mathrm{Md}=2.57)$ there is a decrease, between CG and DTSG there is a more pronounced decrease, $\mathrm{p}>0.05(\mathrm{Mc}=3.37$, $\mathrm{Md}+\mathrm{s}=2.23)$ and between DTG and DTSG, $\mathrm{p}>$ $0.05(\mathrm{Md}=2.57, \mathrm{Md}+\mathrm{s}=2.23)$ it is a slight decrease, but none shows statistically significant differences.

- To demonstrate the effect of the type of intervention on triglycerides, $\mathrm{F}=3.346, \mathrm{p}=0.039$, post-study (after one year) triglycerides are shown to differ significantly in the 3 groups, as seen in Figure 1(b). Between CG and DTSG $\mathrm{p}<0.001$ ( $\mathrm{Mc}=30.27$, $\mathrm{Md}+\mathrm{s}=24.17$ ), which shows significant differences. There are no significant differences between triglycerides at 1 year, recorded at DTG and DTSG, p> $0.05(\mathrm{Md}=0.20, \mathrm{Md} s=0.15)$, but between $\mathrm{CG}$ and DTG $\mathrm{p}<0.001(\mathrm{Mc}=0.45, \mathrm{Md}=0.20)$ are shown significant differences.

- Regarding CRP, $\mathrm{F}=0.581, \mathrm{p}=0.126$, at post-testing (after 1 year) CRP does not differ significantly in the 3 groups, as can be seen in Figure 1(c). Between CG and DTG p>0.05 $(\mathrm{Mc}=0.20, \mathrm{Md}=0.13)$ there is a decrease, between CG and DTSG there is a more pronounced decrease, $\mathrm{p}>0.05(\mathrm{Mc}=0.20$, $\mathrm{Md}+\mathrm{s}=0.09)$ and between DTG and DTSG, $\mathrm{p}>0.05$ $\left(\mathrm{Md}=0.13, \mathrm{Md}^{+} \mathrm{s}=0.09\right)$ a moderate decrease can be observed, but without statistically significant differences.

- In order to verify the effect of the type of intervention on uric acid $\mathrm{F}=0.581, \mathrm{p}=0.561$, at post-test (after one year) it is observed that uric acid levels do not differ significantly in the 3 groups, as it can be seen in Figure 1(d). Between CG and DTG p >0.05 $\left(\mathrm{Mc}_{\mathrm{c}}=0.20, \mathrm{Md}=0.13\right)$ there is a decrease, between CG and DTSG there is a more pronounced decrease, $\mathrm{p}>0.05\left(\mathrm{Mc}=0.20, \mathrm{Md}^{+} \mathrm{s}=0.09\right)$ and between DTG and DTSG, $\mathrm{p}>0.05,(\mathrm{Md}=0.13, \mathrm{Md}+\mathrm{s}=0.09)$ is shown a slight decrease, but none shows statistically significant differences.

In the case of cholesterol, $F=3.588, p=0.031$, at the post-test (after one year) the cholesterol differs significantly in the 3 groups - Figure 1(e). Between CG and DTG $\mathrm{p}<0.001(\mathrm{Mc}=0.65, \mathrm{Md}=0.47)$, between CG and DTSG p $<0.001(\mathrm{Mc}=0.65, \mathrm{Md}+\mathrm{s}=0.48)$, as shown in Figure 1. There are no significant differences between cholesterol, at 1 year, recorded at DTG and DTSG, $\mathrm{p}>0.05(\mathrm{Md}=0.47, \mathrm{Md}+\mathrm{s}=0.48)$, as described in Table 2.

\section{Evolution of the correlation of paraclinical parameters}

For the relationship between the pre-test / post-test difference for uric acid and triglycerides, a Pearson coefficient $\mathrm{r}=0.544$ was obtained, $\mathrm{p}<0.001$, which indicates a strong positive relationship. The smaller the difference in triglycerides, the lower the difference in uric acid. This relationship, with statistical significance, results from the positive value of the Pearson coefficient, but also from the value of statistical significance $<0.05$. A decrease in triglycerides, correlated with a decrease in serum uric acid, is shown in Figure 2(a). The standard deviation in the graphical presentation of the difference of uric acid in relation with the difference of triglycerides shows

Table 2. Descriptive and inferential statistics for the effectiveness of diet therapy and sports on paraclinical parameters.

\begin{tabular}{|c|c|c|c|c|c|c|}
\hline Research variables & Group & $\begin{array}{l}\text { Patients } \\
\text { (no.) }\end{array}$ & Mean & $\begin{array}{l}\text { Standard } \\
\text { deviation }\end{array}$ & $t$ & $p$ \\
\hline \multicolumn{7}{|c|}{ Cholesterol } \\
\hline Initial & \multirow{2}{*}{ CG } & \multirow{2}{*}{20} & 0.65 & 0.48 & \multirow{2}{*}{1.000} & \multirow{2}{*}{1.000} \\
\hline Final & & & 0.65 & 0.48 & & \\
\hline Initial & \multirow{2}{*}{ DTG } & \multirow{2}{*}{58} & 0.72 & 0.45 & \multirow{2}{*}{5.114} & \multirow{2}{*}{0.001} \\
\hline Final & & & 0.32 & 0.47 & & \\
\hline Initial & \multirow{2}{*}{ DTSG } & \multirow{2}{*}{32} & 0.50 & 0.50 & \multirow{2}{*}{1.408} & \multirow{2}{*}{0.169} \\
\hline Final & & & 0.34 & 0.48 & & \\
\hline
\end{tabular}



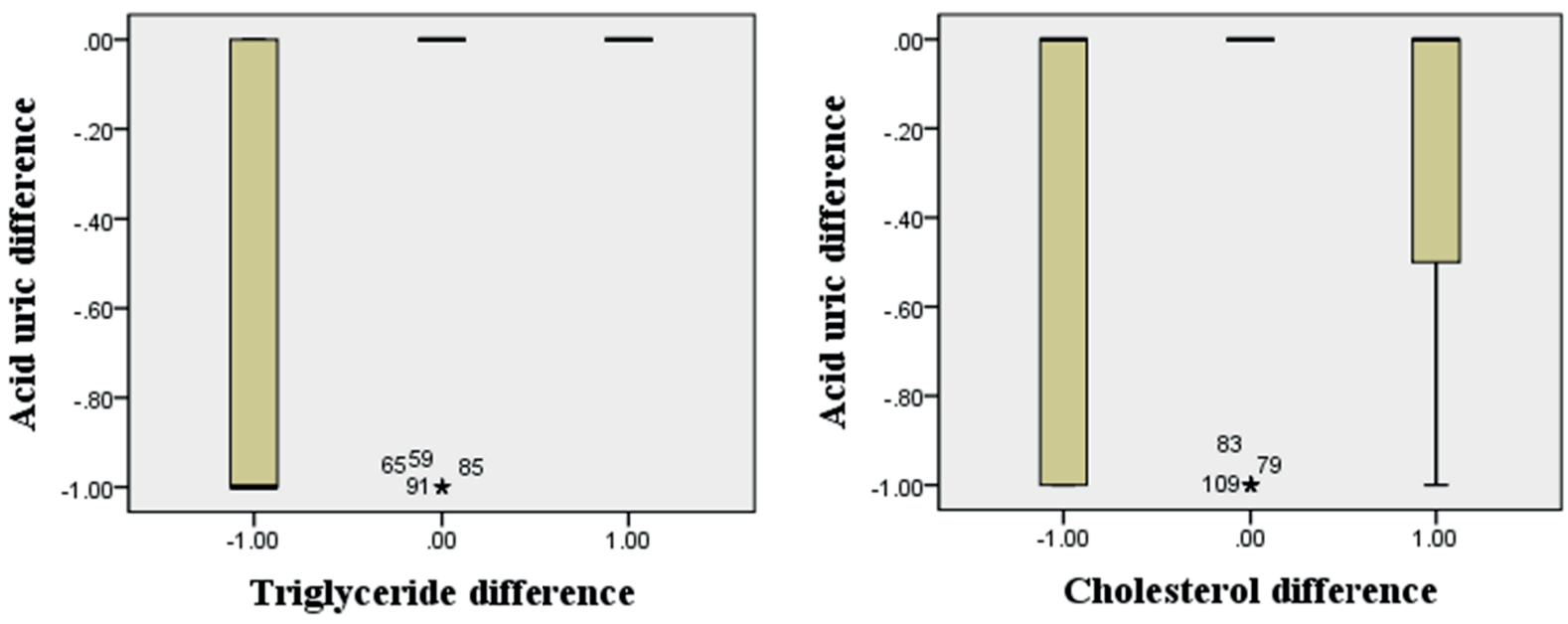

Figure 2. Relationship between differences in (a) uric acid and triglycerides, (b) cholesterol, (c) CRP, and (d) HOMA index in all 3 groups.

that in CG the initial and final value overlap, being only one bar, while in the other 2 groups, DTG and DTSG, a standard deviation can be observed, which indicates a change and a strong relationship. It has mostly changed for DTSG.

For uric acid and cholesterol, as it can be seen in Figure 2(b), was obtained a Pearson coefficient $\mathrm{r}=0.192, \mathrm{p}<0.05$, which indicates a positive relationship. The lower the difference in cholesterol, the lower the difference in uric acid. This relationship, with statistical significance, results from the positive value of the Pearson coefficient, but also with Sig. (statistical significance) $<0.05$. A decrease in cholesterol is correlated with a decrease in serum uric acid.

In the case of uric acid correlated with CRP, a Pearson coefficient $\mathrm{r}=0.443$ ( $\mathrm{p}<0.001$ ) was obtained, shown in Figure 2(c); in the case of the HOMA index, there were obtained statistically significant results, the Pearson coefficient being $\mathrm{r}=0.223$ ( $\mathrm{p}<0.05$ ), described in figure 2(d), which determines a strongly positive and directly proportional connection.

\section{Discussion}

The nutritional and dietary approach combined with regular physical activity raise many questions. In 2013, an article followed the evolution of $\mathrm{MS}^{8}$, publishing the effects of lifestyle changes in patients with diabetes and MS. The results showed the importance of lifestyle change and its beneficial effects in improving the quality of life in people with MS or diabetes. In the present study, was obtained a significant decrease in BMI in both DTG and DTSG, compared to CG. By adjusting the intake of lipids, refined carbohydrates, or excess protein, were obtained statistically significant results in that category. The decrease in
BMI with an average value of 5.77 (from 30.27 in CG, to 24.5 in DTG and 24.17 in DTSG) indicates the jump of a whole weight status category, which means the reduction of fat and visceral fat, the reduction of muscle mass and the improvement of basal metabolism, without physical activity. BMI values in the control group showed a slight increase, from 30.09 to 30.27 , which demonstrates the maintenance of wrong eating habits and a lifestyle that increases the risk of MS-associated diseases ${ }^{9}$, without rational intake of macronutrients. Changes in BMI values at DTG, at the end of the study period, indicate a decrease of 7.13 units, thus highlighting the importance of proper and conscious nutrition in terms of protein, fat, and carbohydrate intake. At DTSG, a BMI value of 24.17 was obtained, lower than in case of simple diet therapy, which suggests that diet therapy combined with sports has a higher efficiency. Visceral fat represents a high-risk in MS, but also in coronary heart disease or diabetes, especially in the postmenopausal period, according to a 2019 study $^{10}$. The correlation between physical activity and visceral fat reduction was significant in the previously mentioned study $(p=0.018)$, the same with the results of the present study $(\mathrm{p}=0.038)$, a statistically significant correlation for the 3 groups.

In this research, there was obtained an average decrease of 1.70 units of the HOMA index at DTSG, from the beginning to the end of the research study. Compared to CG, an average decrease of 1.14 units was obtained, higher than in the group with DTG, which indicates the importance of physical activity in reducing the HOMA index, thus improving the values of paraclinical parameters. In the case of DTSG, there was obtained a decrease of 1.09 units, in the studied period. 
Tracking the paraclinical parameters of MS in the three research groups suggests that dietary change and the introduction of regular physical activity had positive impact on the evolution of parameters, the results being statistically significant (cholesterol $p=0.031$, triglycerides $p=0.039$ ). In the case of CRP and uric acid, although statistically insignificant, a greater decrease in DTSG was observed.

Numerous studies assess the cardiovascular risk through paraclinical monitoring of blood lipids. In the United States, in 2019, a study was published on improving body composition in young people, directly related to the improvement of cholesterol, triglycerides and CRP ${ }^{11}$. Cholesterol and triglycerides levels change significantly, as a result of dietary changes in the dietary therapy group. Insignificant cholesterol lowering in diet and sports therapy can be explained by the association between exercise and hepatic glycogen depletion ${ }^{12}$. Currently, there are no guidelines with standardized nutritional intervention to maximize liver glycogen replenishment. The importance of a balanced diet can be seen by comparing the 3 groups, obtaining a significant decrease in the triglyceride parameter in DTSG. Lowering cholesterol and triglycerides also lowers cardiovascular risk, according to a review published in 2019, which studied the influence of diet on the development of diseases, including cardiovascular disease ${ }^{13}$. In the present study, much lower results were obtained owing to a vegetarian diet with a balanced, low intake of macronutrients of animal origin that was studied.

CRP is correlated with a high mortality risk factor. Some studies associate CRP with several elderly diseases, including MS, diabetes or obesity, but also with cancer and cardiovascular risk ${ }^{14}$. In the group with diet therapy, a statistically significant reduction of CRP was obtained, which implies that diet therapy is an effective monotherapy alternative. A study published in London assessed the link between physical activity and the evolution of CRP over several years $^{15}$. This study highlights a correlation between light physical activity, inversely proportional to the increase in this parameter. The statistically significant result in DTSG is also consistent with that obtained in other studies ${ }^{16}$.

In the case of uric acid, it was obtained a reduction of the initial/ final values in the DTG group, compared to CG. A reduction in the value of this parameter was also observed in DTSG, but this reduction was not substantial enough for statistical significance. The 2019 results of a comparative study had a smaller impact, which can be explained by a balanced diet, but not specific for the reduction of uric acid; in the mentioned study are presented both the values of uric acid and the values depending on the low glycemic index and, as well, in the case of polycystic ovary ${ }^{17}$. Szczuko et al observed that oxidative stress is the main factor linking hyperglycemia with increased protein glycation, activation of protein kinase $\mathrm{C}$, formation of glycosaminoglycans and activation of the transcription factor (NF- $\mathrm{KB}$ ) responsible for the development of inflammation. The link of uric acid with the other parameters explains its more weighted decrease, if neither the HOMA nor CRP index decreased significantly. This result is consistent with the results in the literature. A 2018 study looked at the influence of uric acid on moderate and intense physical activity, and found that patients with high uric acid are negatively influenced in their sports activity, lowering performance, raising blood pressure even in normotensive subjects ${ }^{18}$. These data may explain the results obtained in the present study. In $\mathrm{CG}$, the value of the HOMA index, at the final evaluation (3.37), increased slightly by 0.22 units, which shows the trend of positive evolution of MS, without nutritional or allopathic intervention, as well as without physical activity. In the DTG, the HOMA index decreased by 0.8 units, without statistical significance. Statistically significant results were obtained at DTSG. The association of the HOMA index with the increase in MS and cardiovascular risk was discussed in a 2016 study $^{19}$. Data published in NUTRIENTS tracked the positive effects of diet therapy on the HOMA index ${ }^{20}$. The 2019 results in obese and normal weight Korean subjects show that associating a high value of the HOMA index with physical activity could be a beneficial strategy for health ${ }^{21}$.

Through regular exercise, body weight decreases, insulin sensitivity is stimulated and intramuscular saturated fatty acids are reduced ${ }^{22}$. This article also refers to the association of diet with physical activity to increase the potential of improving body composition.

The present study showed an average decrease of 1.70 units of the HOMA index in DTSG, from the beginning to the end of the study. Compared to $\mathrm{CG}$, it was obtained an average decrease of 1.14 units, higher than in DTG, which indicates the importance of physical activity in reducing the HOMA index, thus improving the values of paraclinical parameters. The HOMA index, correlated with visceral fat, shows a decrease in the difference of the average visceral fat, both in DTG and DTSG, vs. CG, but the decrease is statistically insignificant, according to the $\mathrm{p}$ value obtained $(\mathrm{p}=0.834)$. Published studies show a link between the two parameters with hyperinsulinemia in rats $^{23}$, and with hypercholesterolemia in Japanese-American adults ${ }^{24}$.

Uric acid was significantly correlated with anthropometric parameters (body mass, BMI, reduction in body mass, total body water, arm circumference and 
skin thickness on the shoulder and hip). A positive correlation was observed between uric acid, prolactin and glucose during the diet ${ }^{17}$. Another study looked at the level of triglycerides after the reduction of uric acid in rats and found that, in this situation, the level of triglycerides decreases ${ }^{25}$. Uric acid has been found to be strongly associated with triglycerides, regardless of age, sex, smoking, alcohol consumption, obesity and insulin resistance, in a study published in China ${ }^{26}$. Uric acid and triglyceride levels have also been linked to oxidative stress and mitochondrial dysfunction ${ }^{27}$, but there was also a decrease in the level of uric acid and triglycerides following the administration of glycine and tryptophan without diet therapy $y^{28.30}$.

\section{Conclusions}

Among the risk factors followed by paraclinical parameters (HOMA index, cholesterol, triglycerides, CRP and uric acid) of people with MS, there were statistically significant changes only in the case of cholesterol and triglycerides, in both research groups compared to CG, and to each of the parameters, the final results being compared with the initial values. Cholesterol value (at the end of the study period) changed statistically significant after the dietary intervention, compared to $\mathrm{CG}$, but the association of diet therapy with sport did not lead to statistically significant results either in the case of evaluation against $\mathrm{CG}$ or baseline values, obtaining a decrease, but without reaching the threshold of significance. Regarding the correlation of paraclinical parameters, the statistical analysis performed for uric acid shows a strongly positive and directly proportional correlation with all paraclinical parameters analyzed.

\section{Author Contributions:}

Conceptualization, T.C.G., L.L. and S.B.; methodology, T.C.G. and S.B.; software, T.C.G. and S.B.; validation, T.C.G., L.L. and S.B..; formal analysis, T.C.G., R.A.C.A. and S.B.; investigation, T.C.G., R.A.C.A. and S.B.; resources, T.C.G. and S.B.; data curation, T.C.G. and S.B.; writing-original draft preparation, T.C.G. and S.B.; writing-review and editing, L.L. and S.B,; visualization, S.B.; supervision, S.B.; project administration, S.B. All authors have read and agreed with the final version of this article.

\section{Compliance with Ethics Requirements:}

„The authors declare no conflict of interest regarding this article"

„The authors declare that all the procedures and experiments of this study respect the ethical standards in the Helsinki Declaration of 1975, as revised in 2008(5), as well as the national law. Informed consent was obtained from all the patients included in the study"

„No funding for this study"

\section{Acknowledgements:}

None

\section{References}

1. Kumar S, Behl T, Sachdeva M, et al. Implicating the effect of ketogenic diet as measure to obesity and diabetes mellitus. Life Sciences. 2020. https://doi.org/10.1016/j. lfs.2020.118661

2. Wiesner RJ, Rüegg JC, Morano I. Counting target molecules by exponential polymerase chain reaction: copy number of mitochondrial DNA in rat tissues. Biochemical and Biophysical Research Communications. 1992;183:553-559.

3. Kempler P, Várkonyi T, Körei AE, Horváth VJ. Gastrointestinal autonomic neuropathy in diabetes: the unattended borderline between diabetology and gastroenterology. Diabetologia. 2016;59:401-403.

4. Simon D. Recent advances in clinical allergy and immunology. International Archives of Allergy and Immunology. 2018; 177:324-333.

5. Tchernof A, Després JP. Pathophysiology of human visceral obesity: an update. Physiological Reviews. 2013;93:359-404.

6. Rosqvist F, Iggman D, Kullberg J, et al. Overfeeding polyunsaturated and saturated fat causes distinct effects on liver and visceral fat accumulation in humans. Diabetes. 2014;63:2356-2368.

7. www.Tanita.eu. medical-approved-body-composition-monitors/mc-780-portable-instruction-manual.pdf2020. (Accesed on 13 September 2020).

8. Roberts CK, Hevener AL, Barnard RJ. Metabolic syndrome and insulin resistance: underlying causes and modification by exercise training. Comprehensive Physiology. 2013;3:1-58.

9. Pérez-Martínez P, Mikhailidis DP, Athyros VG, et al. Lifestyle recommendations for the prevention and management of metabolic syndrome: an international panel recommendation. Nutrition Reviews. 2017;75:307-326.

10. Rashti BA, Mehrabani J, Damirchi A, Babaei P. The influence of concurrent training intensity on serum irisin and abdominal fat in postmenopausal women. Przeglad Menopauzalny. 2019;18:166-173.

11. Sattar N, Gaw A, Scherbakova O, et al. Metabolic syndrome with and without C-reactive protein as a predictor of coronary heart disease and diabetes in the West of Scotland Coronary Prevention Study. Circulation. 2003;108:414-419.

12. Gonzalez JT, Fuchs CJ, Betts JA, van Loon LJ. Liver glycogen metabolism during and after prolonged endurance-type exercise. American Journal of Physiology-Endocrinology and Metabolism. 2016;311:E543-553.

13. Glenn AJ, Viguiliouk E, Seider M, et al. Relation of vegetarian dietary patterns with major cardiovascular outcomes: a systematic review and meta-analysis of prospective cohort studies. Frontiers in Nutrition. 2019;6, 80.

14. Li ZH, Zhong WF, Lv YB, et al. Associations of plasma high-sensitivity C-reactive protein concentrations with all-cause and cause-specific mortality among middle-aged and elderly individuals. Immunity $\mathcal{E}$ Ageing. 2019;16:28.

15. Wannamethee SG, Lowe GD, Whincup PH, Rumley A, Walker M, Lennon L. Physical activity and hemostatic 
and inflammatory variables in elderly men. Circulation. 2002;105:1785-1790.

16. Zaha DC, Vesa C, Uivarosan D, et al. Influence of inflammation and adipocyte biochemical markers on the components of metabolic syndrome. Experimental and Therapeutic Medicine. 2020; 20:121-128.

17. Szczuko M, Zapalowska-Chwyć M, Drozd R. A low glycemic index decreases inflammation by increasing the concentration of uric acid and the activity of glutathione peroxidase (GPx3) in patients with polycystic ovary syndrome (PCOS). Molecules. 2019;24(8):1508

18. Jae SY, Bunsawat K, Choi YH, et al. Relation of serum uric acid to an exaggerated systolic blood pressure response to exercise testing in men with normotension. Journal of Clinical Hypertension (Greenwich). 2018;20:551-556.

19. Boyer WR, Johnson TM, Fitzhugh EC, Richardson MR, Churilla JR. The associations between increasing degrees of HOMA-IR and measurements of adiposity among euglycemic U.S. adults. Metabolic Syndrome and Related Disorders. 2016;14:108-113.

20. Ramos-Lopez O, Riezu-Boj JI, Milagro FI, Cuervo M, Goni L, Martinez JA. Interplay of an obesity-based genetic risk score with dietary and endocrine factors on insulin resistance. Nutrients. 2020;12(1):33.

21. An SJ, Jung MH, Ihm SH, Yang YJ, Youn HJ. Effect of physical activity on the cardiometabolic profiles of non-obese and obese subjects: Results from the Korea National Health and Nutritional Examination Survey. PLOS One. 2019;14:e0208189.

22. Bird SR, Hawley JA. Update on the effects of physical activity on insulin sensitivity in humans. BMJ Open Sport $\mathcal{F}^{2}$ Exercise Medicine. 2017; 2:e000143.

23. Pérez-Torres I, Gutiérrez-Alvarez Y, Guarner-Lans V, Díaz-Díaz E, Manzano Pech L, Caballero-Chacón SDC.
Intra-abdominal fat adipocyte hypertrophy through a progressive alteration of lipolysis and lipogenesis in metabolic syndrome Rats. Nutrients. 2019;11(7), 1529.

24. Song SO, Hwang YC, Kahn SE, Leonetti DL, Fujimoto WY, Boyko EJ. Intra-abdominal fat and high density lipoprotein cholesterol are associated in a non-linear pattern in Japanese-Americans. Diabetes $\mathcal{E}$ Metabolism Journal. 2020;44:277-285.

25. Omolekulo TE, Michael OS, Olatunji LA. Dipeptidyl peptidase-4 inhibition protects the liver of insulin-resistant female rats against triglyceride accumulation by suppressing uric acid. Biomedicine ES Pharmacotherapy. 2019;110:869-877.

26. Zhao LJ, Zhao D, Liu J, et al. Association between serum uric acid and triglyceride in a Chinese community. Zhonghua Nei Ke Za Zhi. 2005;44:664-667.

27. Maarman GJ, Andrew BM, Blackhurst DM, Ojuka EO. Melatonin protects against uric acid-induced mitochondrial dysfunction, oxidative stress, and triglyceride accumulation in C2C12 myotubes. Journal of Applied Physiology. 2017;122:1003-1010.

28. Oshima S, Shiiya S, Nakamura Y. Serum uric acid-lowering effects of combined glycine and tryptophan treatments in subjects with mild hyperuricemia: a randomized, double-blind, placebo-controlled, crossover study. Nutrients. 2019;11(3):564.

29. Epingeac ME, Gaman MA, Diaconu C, Gad M, Gaman AM. The evaluation of oxidative stress in obesity. Rev Chim (Bucharest) 2019;70(6):2241-2244.

30. Diaconu C, Nastasa A, Zaki AR, Arsalan M. Type 2 diabetes: a driver for chronic heart failure. The $2^{\text {nd }}$ International Conference on Interdisciplinary Management of Diabetes Mellitus and its Complications - Diabetes mellitus as cardiovascular disease, INTERDIAB 2016 Proceedings, pp. 201-210. Ed. Niculescu. Editors Serafinceanu C, Negoita O, Elian V. 